\title{
Treatment of Voice Disorders in Children
}

\author{
By: Celia R. Hooper ${ }^{*}$
}

Hooper, C.R. (2004) Treatment of Voice Disorders in Children, Language Speech and Hearing Services in Schools, 35, 320-326.

\section{***Note: Figures may be missing for this format of the document ***Note: Footnotes and endnotes indicated with parentheses}

\begin{abstract}
:
Children with voice disorders do respond to treatment, with vocal hyperfunction being the predominant disorder on the caseload of the pediatric voice clinician. This article reviews the literature in describing what is known about these children and typical disorders, prevention of voice disorders, the need for treatment, the referral patterns of teachers and others, and typical management programs and their settings. Good online resources are offered and brief highlights about voice therapy with children are reviewed.
\end{abstract}

\section{Article:}

Children with voice disorders do respond to treatment, but accurate prevalence and incidence data are not entirely known. Clinicians report that treatment is important to prevent future problems in adolescence and adulthood, but data are not available to support the premise that childhood voice disorders continue into adulthood. In addition to those medically complex children with voice disorders (Woodnorth, 2004), there are a significant number with vocal hyperfunction, with and without other co-occurring speech and language disorders. Ramig and Verdolini (1998) reported evidence for successful treatment of voice disorders in child and adolescent populations; more recently, there are reports of successful treatment of children with surgery, aggressive respiratory care, vocal hygiene programs, and direct voice therapy (Baker \& Blackwell, 2004; Mori, 1999; Sandage \& Zelazny, 2004). Teacher and parent referral to the school speech-language pathologist (SLP) and acceptance of the child with a voice disorder on the school caseload/workload may continue to be problematic in this population until the academic and social ramifications of a disordered voice are appreciated. This article is designed to provide answers to common questions about voice disorders and treatment.

\section{WHAT ARE VOICE DISORDERS?}

According to Ramig and Verdolini (1998), voice disorders are generally characterized by an abnormal pitch, loudness, and/or vocal quality resulting from a disordered laryngeal, respiratory, and/or vocal tract functioning. Voice disorders range from a mild hoarseness to complete voice loss and may limit the intelligibility or effectiveness of oral communication. Voice disorders may be due to habits of vocal misuse and hyperfunction (e.g., improper use of the larynx, such as excessive throat clearing, yelling, prolonged talking over loud background noise, muscular imbalances) commonly producing physical changes in the vocal folds, other medical/physical conditions (e.g., trauma, neurological

\footnotetext{
* The University of North Carolina at Greensboro
} 
disorders, allergies), or psychological factors (e.g., stress, conversion reactions, personality disorders). It is not uncommon for a voice disorder to reflect a combination of these factors. (S101-S102)

\section{WHO ARE THE CHILDREN WITH VOICE DISORDERS?}

Ramig and Verdolini (1998) defined characteristics of, causes of, and degrees of severity of voice disorders. According to Senturia and Wilson (1968) and Silverman and Zimmer (1975), the frequency of occurrence of voice disorders in children ranges from $6 \%$ to 23.4\%. Powell, Filter, and Williams (1989) screened 847 children, ages 6- 10 years, in the Warren County Public School System in Virginia for phonatory disorders three times over 5 years and found that $23 \%$ of the children (203) had voice disorders initially, and after 5 years, 19 of the 203 children still had a voice disorder, with none of the children receiving treatment. Mori (1999), however, in a retrospective survey of 259 Japanese children or their parents, indicated that voice problems may resolve at or before puberty, although these data were incomplete.

School SLPs in the United States have reported that children with voice disorders constitute $2 \%$ to $4 \%$ of their caseloads (Deal, McClain, \& Sudderth, 1976; McNamara \& Perry, 1994). A recent survey of one primary care trust in the United Kingdom indicated a prevalence of $2 \%$ of voice referrals in children, but this was a health care setting, not a school setting (Broomfield \& Dodd, 2004). Most authors agree that anywhere from $1 \%$ to 23.4\% of children have a voice disorder (Deal et al., 1976; McNamara \& Perry, 1994; Powell et al., 1989; Senturia \& Wilson, 1968; Silverman \& Zimmer, 1975) at any given time (incidence), and somewhere between $6 \%$ to $9 \%$ is the best estimate of prevalence (McNamara \& Perry, 1994). The incidence of vocal pathology in adolescents may exceed these estimates (Peppard, 1996). It is likely that the numbers vary so widely because of a lack of consistency in measurement, as well as variability in listener perceptual judgment.

\section{What Types of Voice Problems Do Children Have?}

Ramig and Verdolini (1998) reviewed data on the frequency of occurrence of various types of voice disorders. The majority of these cases were hyperfunctional voice disorders. The estimated portion of school voice caseloads related to vocal abuse/misuse is the following: "most," 44\%; "some," $34 \%$; and "none," $22 \%$ (McNamara \& Perry, 1994). The prevalence of elementary-age children presenting symptoms of chronic hoarseness has been shown to be as high as $38 \%$ (Harden as cited in Leeper, 1992). Andrews (1995) and Glaze (1996) reported that hyperfunction is the most likely disorder seen in children, and Peppard (1996) used the term functional disorders.

The McNamara and Perry (1994) survey indicated that most portions of voice caseloads in schools were related to vocal abuse/misuse. Vocal nodules are the cause of between $45 \%$ and $80 \%$ of childhood dysphonias (Baynes, 1966; Herrington-Hall, Lee, Stemple, Niemi, \& McHone, 1988). St. Louis, Hansen, Buch, and Oliver (1992) found that the majority of students in grades 1 through 12 with either severe or moderate voice disorders exhibited hoarseness. Hoarseness is a frequent presenting symptom of hyperfunctional voice disorders, but it can also signify an "organic pathology" (Glaze, 1996). Functional voice 
disorders that are likely to occur in adolescence are functional aphonia and persistent falsetto, or puberphonia, though few reports have been made (Peppard, 1996). Articulation disorders, language disorders, and mild hearing problems are likely to coexist with voice disorders (St. Louis et al., 1992). Upper respiratory tract infections, allergies, and asthma are likely to co-occur with hoarseness in children (Greene \& Mathieson, 2001); gastroesophageal reflux may also contribute to hoarseness (Koufman, Sataloff, \& Touhill, 1996).

\section{Can Voice Disorders in Children Be Prevented?}

Voice disorders and many of their primary causes are amenable to prevention practices of either primary or secondary focus (Kahane \& Mayo, 1989; Marge, 1991; McNamara \& Perry, 1994; Mori, 1999). McNamara and Perry found that 27 of 145 (19\%) school-based SLPs had worked on vocal abuse/misuse prevention with groups of students, primarily with elementary students, in the 2 years before the survey. However, $59 \%$ of respondents agreed that prevention programs were a cost- and time-effective means to manage voice disorders secondary to vocal abuse and misuse. Most SLPs in this study and later follow-up surveys thought that they did not have the time required for prevention practices, nor did all of them think that prevention of voice disorders carried a high priority in the school setting (Clark, 2003). Some SLPs in the schools, in consultation with classroom teachers, provide prevention information as part of the regular curriculum. Examples include information during the standard curriculum topic of "the respiratory system" in later elementary years and "taking care of your body" in the earlier grades. There are no data on prevention programs in preschools.

\section{DO CHILDREN NEED VOICE TREATMENT?}

Treatment of voice disorders in children is warranted. Powell et al.'s (1989) longitudinal study of the prevalence of voice disorders in children indicated that many students continued to present with a voice disorder 5 years after their initial screening. Furthermore, more than half of those showed voice severity ratings that were more severe than mild. None of these children was enrolled in voice treatment during the span of the study. Moran and Pentz (1987) found that 59\% of the otolaryngologists that they sampled preferred voice treatment as the sole means of treatment for vocal nodules in children. Of 31 school-age children in voice treatment for vocal nodules, $68 \%$ had reduced nodule size and $23 \%$ had normal larynges after 2 months of treatment. Four months later, $84 \%$ had reduced nodule size and 65\% had normal larynges (Deal et al., 1976).

The speech of children with voice disorders influences adults' perceptions of their nonspeech characteristics, with the listener perceiving these children as more negative than children with normal speech (Ruscello, Lass, \& Podbesek, 1988). Voice disorders can affect a child's ability to function in the classroom, where oral communication is "continuous" (Leeper, 1992). Children with voice disorders may be perceived as having behavioral problems or as being more aggressive than their peers. In addition, children and adolescents are affected by voice disorders in their peers in much the same way, although to a lesser degree (Lass, Ruscello, Bradshaw, \& Blankenship, 1991). Experienced classroom teachers are aware of these negative effects (Davis \& Harris, 1992), both socially and academically (Bennett \& Runyan, 1982). Davis and Harris found that 
elementary classroom teachers could consistently identify children with voice disorders, indicating that classroom teachers are good referral sources.

\section{Should We Treat Childhood Voice Disorders? Is There Evidence That It Is Effective and "Worth It?"}

The data to answer this question are somewhat confusing. In a group of 64 children who had been diagnosed with phonatory voice disorders, 40 were reevaluated 1 year later, with $33 \%$ not showing any improvement (Filter \& Poyner as cited in Powell et al., 1989). The authors attributed this finding to the fact that the children were not placed in voice rehabilitation. In a longitudinal study in a Virginia county school system, 847 children were screened and 203 , or $23.9 \%$, had some form of voice disorder-17\% phonatory, $6.9 \%$ hypernasal. One year later, 178 were reevaluated and 71, or 39.9\%, still showed noticeable voice disorder. Four years later, 50 children were reevaluated and 19, or 38\%, still showed voice problem; 11 of the 19 showed voice severity ratings more severe than "mild" or “just-noticeable." None were enrolled in treatment (Powell et al., 1989).

\section{Do Teachers Identify or Refer Children With Voice Disorders?}

Elementary classroom teachers can consistently identify children with disordered voices; $86 \%$ of teachers' judgments of normal voices indicated that the samples were normal; $82 \%$ of teachers' judgments of disordered voices indicated that the samples were disordered (Davis \& Harris, 1992). Teachers themselves are at high risk for voice disorders (Roy et al., 2004), and many may exhibit poor vocal habits/disordered voices, presenting both a poor model for students and clouded perceptions for referral. There are no group published data regarding teacher referral, so this question has not been answered.

\section{Is There a Controversy in Placing Children in Voice Therapy in the Schools?}

Few children are placed in direct voice rehabilitation because either the voice disorder was not considered "severe enough" or the school SLPs did not consider these children as having a high priority for placement on the active caseload (Powell et al., 1989). SLPs in the schools are more likely to take dysphonic children on their school caseloads if they have the Certificate of Clinical Competence from the American Speech-Language-Hearing Association (ASHA) and if they have attended a workshop on voice disorders in the past 3 years (Clark, 2003). Clark also found that acceptance of these children on the caseload was not affected by years since graduate school or years of clinical experience.

There are differing opinions among SLPs, parents, and children regarding perceived voice quality, concern about voice problems, and priority/concern assigned to voice problems (McNamara \& Perry, 1994). School-based clinicians complain of difficulty obtaining laryngoscopic examinations for a variety of reasons: (a) lack of parental follow-up; (b) lack of physician follow-up referral to specialist; (c) difficulty in obtaining relevant information on the results of a laryngeal examination; (d) need for specific information on vocal production not usually provided by medical examination; (e) perceived lack of resources in rural areas and small towns; (f) lack of education on this topic-for themselves, parents, and medical professionals; and ( $\mathrm{g}$ ) need for improvement of interprofessional communication between SLPs, school nurses, pediatricians, and otolaryngologists (Leeper, 1992). Difficulty getting laryngeal examinations caused either (a) children placed on a waiting list 
for service indefinitely or (b) delivery of treatment based on an incomplete diagnosis of a child's voice disorder (Clark, 2003; Leeper, 1992). Because video stroboscopic endoscopy is the "diagnostic gold standard" (Behrman, 2003), this presents quite a dilemma for the school-based clinician.

\section{What Percentage of Dysphonic Children Are Seen for Therapy?}

McNamara and Perry (1994) reported that only $1 \%$ of dysphonic children are seen for treatment by SLPs. But, others reported that the portion of school SLPs' caseloads filled by voice clients was somewhat higher, with Clark (2003) reporting 2\% and Davis and Harris (1992) reporting $2 \%$ to $4 \%$.

\section{Are School SLPS Treating Children With Voice Disorders?}

The literature presents a confusing state of affairs in voice referral and management in children. As mentioned above, 59\% of school-based SLPs agreed that prevention is an efficient way to treat vocal abuse/misuse, yet only 19\% performed such practices (McNamara \& Perry, 1994). In Powell et al.'s (1989) initial public school system voice screening, "few, if any" of the children who had been identified with a voice disorder received direct voice treatment. Clark (2003) found that school SLPs with more experience (academic and clinical) in voice disorders were more likely to treat these children, but many of them did not communicate with an otolaryngologist. Oddly enough, the SLPs with larger caseloads were more likely to serve children with voice disorders. Clinicians in the public schools are restricted by performance on a set of standardized speech and language assessments. There is no clear means of defining vocal quality in terms of a standard deviation, and thus qualifying a child for services under those restrictions is quite difficult (see Ruddy \& Sapienza, 2004).

Public school-based clinicians have expressed other barriers in treating these children, including difficulty in obtaining laryngoscopic examinations of children with voice disorders before the initiation of voice treatment, lack of parental or physician follow-up of the SLPs' recommendations; lack of resources in rural areas; lack of education on the part of administrators, parents, and medical professionals; and a need for improvement of interprofessional communication between SLPs, school nurses, pediatricians, and otolaryngologists. The results of these difficulties were either postponement of voice treatment indefinitely or provision of voice treatment without the knowledge of a complete diagnosis (Clark, 2003; Leeper, 1992). Teacher referrals have not always been

forthcoming, and many investigators recommend a school screening program that includes voice disorders (see Lee, Stemple, Glaze, \& Kelchner, 2004). Ramig and Verdolini (1998) discussed a team model of an SLP and an ear, nose, and an otolaryngologist. Some school systems in the United States have adopted this screening/diagnosis model, having the otolaryngologist visit the school on a "clinic day."

\section{HOW DOES VOICE THERAPY DIFFER IN CHILDREN? DO WE TREAT CHILDREN LIKE SMALLER ADULTS?}

There are some important differences between voice management, and therapy, in children and in adults. First, the development of voice, like the development of language, assumes normal expressive and receptive learning. If anything goes wrong in that development, it 
can have lifelong implications for other behaviors. Unlike the adult, who may have had normal voice and wishes to return to that normal production, some children may not ever have had normal voice production. Therefore, they may not have an internal representation or memory of "normal voice." This may affect motivation for change or even the realization that some behavior needs changing. Unlike the child with severely disordered articulation or language, the child with a moderate or severe voice disorder can, many times, still be understood by the listener. Thus, the apparent need to alter the speech production may not be present. There have been many developments in technology to assist the clinician in helping the child with a voice disorder understand his or her voice production and help the child become motivated for change.

Voice clinicians who work with children have a variety of therapeutic programs from which to choose, but most clinicians advocate the use of several phases of therapy: a general awareness of vocal behaviors, specific awareness of behaviors to change, direct voice therapy or vocal production activities, and generalization or carryover activities (Andrews \& Summers, 2002). Andrews (1995), Andrews and Summers (2002), and Glaze (1996) all provided a variety of activities to achieve these goals, altering the literacy level and the information to be age appropriate. Some voice programs, like the Boone Voice Therapy Program for Children (Boone, 1993), offer a "cognitive program" for general and specific awareness of behaviors and include a variety of media that children would enjoy. New technologies, such as the "voice games" by Kay Elemetrics, which come as software packages with the Computerized Speech Lab and the Visi-Pitch IV, offer cliniciancustomizable computer games that motivate children with activities for voicing, timing, pitch level and control, and amplitude control (Kay Elemetrics, 2004). Some creative materials, such as Ertmer's Web site featuring the stages of vocal development (Ertmer, 2004), offer clinicians normal models of vocal development as well as some insight as to why voice disorders might coincide with articulation, resonance, and language disorders for better therapy planning.

Most therapy programs advocate the use of insight and discussion or direct activities related to interpersonal skills as they relate to voice, including such behaviors as interrupting, turn taking, appropriate loudness, and voice and emotion. All programs include an adult, whether it be the parent, peer, teacher, or other significant listener in the child's life. Most authors address treatment of the teenager in relation to more vocally risky behaviors that may occur in the teen years, including cheerleading, shouting during sports, and smoking, and include these behaviors in a vocal hygiene treatment program. Programs for children and teens address vocal image and self-perception of "the good voice." Older teens may receive voice therapy similar to that provided to adults. To date, there has not been a large-scale investigation of the efficacy of any given therapy program with a child with a particular type of voice disorder.

What Are the Most Effective Treatment Programs for Voice Disorders in Children? To date, there has not been a large-scale survey to describe the exact numbers of pediatric management programs or centers for children, but anecdotal information from published newsletters of ASHA's Special Interest Division 3: Voice and Voice Disorders indicates that most preschool children, and many school-age children, are seen in hospitals, health 
centers, university clinics, and private practices, usually referred by parents or preschool teachers to SLPs via medical referral. School-age children may be seen by school SLPs or they may be seen after school and in the summer by a clinician based in a health care or private setting.

The most common management programs, in addition to primary prevention programs, include secondary prevention/ vocal hygiene programs, direct voice therapy, and surgery in combination with vocal hygiene and/or direct voice therapy. Pediatric voice specialists agree that the most common causes of voice disorders in children are secondary to vocal trauma, including shouting incorrectly, screaming, talking loudly, making vocal noises, and clearing the throat excessively. These children are typically treated by medical intervention (such as those related to allergies and asthma), vocal hygiene or education programs, and direct voice therapy. Rarely is surgery for vocal nodules, the most common childhood voice disorder, recommended (Colton \& Casper, 1996). A review of frequently used texts in voice disorders, including those covering pediatric information exclusively and those covering the lifespan, have common themes in treatment (Andrews, 1995; Andrews \& Summers, 2002; Boone \& McFarlane, 2000; Colton \& Casper, 1996; Dworkin \& Meleca, 1997; Stemple, 2000; Stemple, Glaze, \& Klaben, 2000). These include the following:

- parent/family involvement

- teacher involvement in the school-age child

- a component of child/family lifestyle education or vocal hygiene education

- psychodynamic and interpersonal factors and related behavioral intervention or discussion

- the incorporation of vocal behavior into good language and communication behavior

- the use of age-appropriate activities if direct voice therapy is recommended Each of these texts reviews common therapy goals, with some of them focusing on special at-risk subgroups of children and some of them including recommended activities that appeal most to children. Most authors recognize that a challenge in voice therapy with children is motivation for vocal change if a need for that change is not recognized. Thus, there are many activities for recognition and general awareness of the disorder (Andrews \& Summers, 2002), charting and rewarding self-recognition of behavior (Boone \&

McFarlane, 2000), and understanding normal phonatory and respiratory behavior via visually appealing materials (Rammage, 1996). In the past 10 years, many clinical software manufacturers and computer-based hardware manufacturers have produced commercial products with therapeutic computer "games" for children for use in voice therapy (see http://www.mnsu.edu/dept/comdis). Additionally, there are many Internet links with visual information and interactive Web sites for children to learn about respiration and phonation that the clinician can use in management, whether prevention or treatment. To date, there is no evidence that computer-based materials are more effective than traditional materials in the treatment of voice disorders.

Finally, although Ramig and Verdolini (1998) reviewed the literature in voice therapy very well to that date, much more is needed for better evidence of the efficacy of treatment in children. Although Mori (1999) did find that children improved with both vocal hygiene and voice therapy, a retrospective survey method was used, and one cannot be certain that 
(a) therapy was actually effective and (b) what type of therapy was done. Some promising findings for the future include laryngeal biofeedback with and without traditional voice therapy (Van Lierde, Claeys, DeBodt, \& Van Cauwenberge, 2004). New information from videostroboscopic endoscopy, vocal fold histopathology, and vibratory characteristics in the developing vocal folds, as well as new nomenclature in voice science and otolaryngology, are likely to change how one conducts treatment investigations in the future (Behrman, 2003). And, as in the case with adults, the functional outcome questions continue to exist. How do we know which child will be a good candidate for voice therapy and which therapy do we choose? As the profession of speech-language pathology moves with other clinical fields toward evidence-based practice, better models for research design and models that include the clinician and the researcher (often the same person) will guide us toward better information in voice management of children (Apel \& Self, 2003).

\section{ACKNOWLEDGMENT}

The author would like to acknowledge the work of Mary Kristen Clark, graduate research assistant at the University of North Carolina at Chapel Hill, who completed her master's thesis, School Speech-Language Pathology Coverage of Voice Services: Sample NC Counties, May 2003, and the work of Adrienne Sherrill, graduate research assistant at The University of North Carolina at Greensboro, both of whom added to the information in this manuscript. This project was supported by an intramural grant from the University of North Carolina at Greensboro, Office of Research, 2004.

\section{REFERENCES}

- Andrews, M. L. (1995). Manual of voice treatment: Pediatrics through geriatrics. San Diego, CA: Singular.

- Andrews, M. L., \& Summers, A. C. (2002). Voice treatment for children and adolescents. Canada: Singular Thomson Learning.

- Apel, K., \& Self, T. (2003). Evidence-based practice: The marriage of research and clinical services. Retrieved July 9, 2004, from http://www.asha.org/about/publications/leader-nline/ archives/2003/q3/030909.htm

- Baker, B. M., \& Blackwell, P. B. (2004). Identification and remediation of pediatric fluency and voice disorders. Journal of Pediatric Health Care, 18, 87-94.

- Baynes, R. A. (1966). An incidence study of chronic hoarseness among children. Journal of Speech and Hearing Research, 31, 172-176.

- Behrman, A. (2003). Efficacy of voice therapy for vocal fold nodules: Collecting the evidence. ASHA Special Interest Division III: Voice and Voice Disorders Newsletter, 13, 3-6.

- Bennett, C. W., \& Runyan, C. M. (1982). Educators' perceptions of the effects of communication disorders upon educational performance. Language, Speech, and Hearing Services in Schools, 13, 260-263.

- Boone, D. A. (1993). Boone voice therapy program for children. (2nd ed.). Austin, TX: Pro-Ed.

- Boone, D. A., \& McFarlane, S. C. (2000). The voice and voice therapy (6th ed.). Boston: Allyn \& Bacon. 
- Broomfield, J., \& Dodd, B. (2004). Children with speech and language disability: Caseload characteristics. International Journal of Language and Communication Disorders, 39, 303-325.

- Clark, M. K. (2003). School SLP coverage of voice services: Sample NC counties. Unpublished master's thesis, The University of North Carolina at Chapel Hill.

- Colton, R. H., \& Casper, J. K. (1996). Understanding voice problems: A physiological perspective for diagnosis and treatment (2nd ed.). Philadelphia: Lippincott Williams \& Wilkins.

- Davis, C. N., \& Harris, T. B. (1992). Teachers' ability to accurately identify disordered voices. Language, Speech, and Hearing Services in Schools, 23, 136140.

- Deal, R. E., McClain, B., \& Sudderth, J. F. (1976). Identification, evaluation, therapy and follow-up for children with vocal cord nodules in a public school setting. Journal of Speech and Hearing Disorders, 41, 390-397.

- Dworkin, J. P., \& Meleca, R. J. (1997). Vocal pathologies: Diagnosis, treatment, and case studies. San Diego, CA: Singular.

- Ertmer, D. (2004). Vocaldevelopment.com. Retrieved July 30, 2004, from http://www.vocaldevelopment.com/

- Glaze, L. E. (1996). Treatment of voice hyperfunction in the preadolescent. Language, Speech, and Hearing Services in Schools, 27, 244-250.

- Greene, M. C. L., \& Mathieson, L. (2001). The voice and its disorders (6th ed.) New York: Thieme.

- Herrington-Hall, B. L., Lee, L., Stemple, J. C., Niemi, K. R., \& McHone, M. M. (1988). Descriptions of laryngeal pathologies by age, sex, and occupation in a treatment-seeking sample. Journal of Speech and Hearing Disorders, 53, 57-64.

- Kahane, J. C., \& Mayo, R. (1989). The need for aggressive pursuit of healthy childhood voices. Language, Speech, and Hearing Services in Schools, 20, 102107.

- Kay Elemetrics. (2004). Computerized Speech Lab, Model 4500 [Computer software]. Lincoln Park, NJ: Author.

- Koufman, J. A., Sataloff, R. T., \& Touhill, R. (1996) Laryngopharyngeal reflux: Consensus conference report. Journal of Voice, 10, 215-216.

- Lass, N. J., Ruscello, D. M., Bradshaw, K. H., \& Blankenship, B. L. (1991). Adolescents' perceptions of normal and voice- disordered children. Journal of Communication Disorders, 24, 267-274.

- Lee, L., Stemple, J. C., Glaze, L., \& Kelchner, L. N. (2004). Quick Screen for Voice and supplementary documents for identifying pediatric voice disorders. Language, Speech, and Hearing Services in Schools, 35, 308-319.

- Leeper, L. H. (1992). Diagnostic examination of children with voice disorders: A low-cost solution. Language, Speech, and Hearing Services in Schools, 23, 353360 .

- Marge, M. (1991). Introduction to the prevention and epidemiology of voice disorders. Seminars in Speech and Language, 12, 49-72. 
- McNamara, A. P., \& Perry, C. K. (1994). Vocal abuse prevention practices: A national survey of school-based speech-language pathologists. Language, Speech, and Hearing Services in Schools, 25, 105-111.

- Moran, M. J., \& Pentz, A. L. (1987). Otolaryngologists' opinions of voice therapy for vocal nodules in children. Language, Speech, and Hearing Services in Schools, $18,172-178$.

- Mori, K. (1999). Vocal fold nodules in children: Preferable therapy. International Journal of Pediatric Otorhinolaryngology, 49, 303-306.

- Peppard, R. C. (1996). Management of functional voice disorders in adolescents. Language, Speech, and Hearing Services in Schools, 27, 257-270.

- Powell, M., Filter, M. D., \& Williams, B. (1989). A longitudinal study of the prevalence of voice disorders in children from

- a rural school division. Journal of Communication Disorders, 22, 375-382.

- Ramig, L. O., \& Verdolini, K. (1998). Treatment efficacy: Voice disorders. Journal of Speech, Language, and Hearing Research, 41, S101-S117.

- Rammage, L. (1996). Vocalizing with ease: A self-improvement guide. Vancouver, BC: Pacific Voice Clinic.

- Roy, N., Merrill, R. M., Thibeault, S., Parsa, R. A., Gray, S. D., \& Smith, E. M. (2004). Prevalence of voice disorders in teachers and the general population. Journal of Speech, Language, and Hearing Research, 47, 281-293.

- Ruddy, B. H., \& Sapienza, C. M. (2004). Treating voice disorders in the schoolbased setting: Working within the framework of IDEA. Language, Speech, and Hearing Services in Schools, 35, 327-332.

- Ruscello, D. M., Lass, N. J., \& Podbesek, J. (1988). Listeners' perceptions of normal and voice-disordered children. Folia Phoniatrica, 40, 290-296.

- Sandage, M. J., \& Zelazny, S. K. (2004). Paradoxical vocal fold motion in children and adolescents. Language, Speech, and Hearing Services in Schools, 35, 353-362.

- Senturia, B. H., \& Wilson, F. B. (1968). Otorhinolaryngologic findings in children with voice deviation. Preliminary report. Annals of Otology, Rhinology, and Laryngology, 77, 1027-1042.

- Silverman, E. M., \& Zimmer, C. H. (1975). Incidence of chronic hoarseness among school-aged children. Journal of Speech and Hearing Disorders, 40, 211-215.

- Stemple, J. C. (2000). Voice therapy: Clinical studies (2nd ed.). San Diego, CA: Singular.

- Stemple, J. C., Glaze, L. E., \& Klaben, B. G. (2000). Clinical voice pathology: Theory and management (2nd ed.). San Diego, CA: Singular.

- St. Louis, K. O., Hansen, G. R., Buch, J. L., \& Oliver, T. L. (1992). Voice deviations and coexisting communication disorders. Language, Speech, and Hearing Services in Schools, 23, 82-87.

- Van Lierde, K. M., Claeys, S., DeBodt, M., \& Van Cauwenberge, P. (2004). Outcome of laryngeal velopharyngeal biofeedback treatment in children and young adults: A pilot study. Journal of Voice, 18, 97-106.

- Woodnorth, G. H. (2004). Assessing and managing medically fragile children: Tracheostomy and ventilatory support. Language, Speech, and Hearing Services in Schools, 35, 363-372. 
APPENDIX. GOOD ONLINE SOURCES FOR CLINICIANS, TEACHERS, STUDENTS, AND/OR THEIR FAMILIES

- From the American Speech-Language Hearing Association (ASHA), Questions and Answers About Voice Disorders, 2004, http://www.asha.org/public/speech/disorders/Voice-problems.htm; retrieved July 6, 2004.

- Also from ASHA, Nodules and Polyps, 2004, http:// www.asha.org/public/speech/disorders/nodules - polyps.htm; retrieved July 6 , 2004.

- From the University of Washington Department of Otolaryngology-Head and Neck Surgery, 2002, simple, clear pictures of the larynx and vocal folds, http://depts.washington.edu/otoweb/patients/pts - specialties/ pts-voice-prob/ptsvoice-prob.htm; retrieved July 6, 2004.

- From the University of Pittsburgh Voice Center, 2001, clear multimedia pictures of vocal pathology for use with older children or teachers, http://www.upmc.edu/upmcvoice/ Multimedia.htm; retrieved July 6, 2004.

- From the San Diego Center for Voice and Swallowing, 2004, anatomy of the human voice, with Real One video and sound, http://www.sandiegovoice.org/anatomy.html; retrieved July 6, 2004.

- From Branski and Murray, 2004, e-medicine.com article with a description of the types of voice therapy, most of which are used with children and adolescents, with links in the bibliography to many voice articles, http://www.emedicine.com/ent/ topic683.htm; retrieved July 6, 2004.

- From kidshealth.org, 2004, a good answer to "Why am I hoarse?" http://kidshealth.org/kid/ill—injure/sick/laryngitis.html; retrieved July 6, 2004, and "What is an adam's apple? (with

good information about drinking water and a brief explanation of puberty), http://kidshealth.org/kid/talk/qa/adams_-apple.html; retrieved July 6, 2004.

- From the American Academy of Otolaryngology-Head and Neck Surgery, 2003, reflux and children, http://www.entnet.org/ KidsENT/LPR.cfm; retrieved July 6, 2004.

- For teachers' vocal health, an outstanding interactive link, The Voice Academy, 2003, sponsored by the National Center for Voice and Speech, http://rtweb.its.uiowa.edu/vaweb/ voiceacademy.html; retrieved July 6, 2004.

- For preschool teachers, a voice disorders class project by Kristen Matthis, graduate student at the University of North Carolina at Greensboro, 2004, http://www.uncg.edu/ crhooper/ classes/voice/management/PreschoolTeachers.html; retrieved July 6, 2004.

- Therapy materials and classroom materials free on the Internet, links by Judith Kuster, CCC-SLP, an award-winning site, http:// www.mnsu.edu/dept/comdis/kuster2/sptherapy.html; retrieved July 6, 2004, links to commercial products that include voice therapy workbooks and materials for children, http:// www.mnsu.edu/comdis/kuster2/commercial.html; retrieved July 6, 2004.

- The Web site of The National Center for Voice and Speech (NCVS), at http://www.ncvs.org/ has a link from the main page for "young explorers," 
http://www.ncvs.org/ncvs/tutorials/ youngexp/index.html, both retrieved July 28, 2004, which includes enjoyable information about the voice (including burping and hiccupping!) for children of all ages. 